\title{
Fotovoltaik Panel ile Beslenebilen SynRM Tasarımı ve Kontrolü
}

\author{
Güllü BOZTAŞ ${ }^{*}$, Ömür AYDOĞMUŞ², Hanifi GÜLDEMİR \\ 1,3 Elektrik-Elektronik Mühendisliği, Teknoloji Fakültesi, Fırat Üniversitesi, Elazığ, Türkiye \\ ${ }^{2}$ Mekatronik Mühendisliği, Teknoloji Fakültesi, Fırat Üniversitesi, Elazığ, Türkiye \\ ${ }^{* 1}$ gboztas@ firat.edu.tr, ${ }^{2}$ oaydogmus@ firat.edu.tr, ${ }^{3}$ hguldemir@ firat.edu.tr
}

\begin{abstract}
Öz: Senkron Relüktans Motor (SynRM) sağlam ve basit yapı, düşük maliyetli üretim, birim hacim başına yüksek moment imkânı, kontrol basitliği, alan zayıflatma kabiliyeti ve rotor sargılarının bulunmaması nedeniyle azalan kayıplar gibi birçok avantaja sahiptir. Bu yüzden, bu motorlar çok sayıda endüstriyel ve otomotiv uygulamalar için ilgi çekici hale gelmeye başlamıştır. Düşük çap ve düşük gerilime sahip bir motor ile yüksek moment üretilmesi oldukça zordur. Bu makalede; fotovoltaik (PV) panellerin ürettiği düşük gerilim seviyesiyle çalışabilen bir SynRM tasarımı amaçlanmışır. Bu motor iyi bir dinamiğe sahip, yüksek kalkış momentli ve yüksek verimli bir motor olarak tasarlanmıştır. Motor, akım başına düşen maksimum moment (MTPA) kontrol algoritması ile kontrol edilmiştir. Ayrıca panellerden maksimum güç elde edilebilmesi için Maksimum Güç Noktası İzleme (MPPT) algoritması kullanılmıştır. Bu algoritma motorun hız-referans bilgisini otomatik olarak değiştirerek sistemin maksimum verimde çalışmasını sağlamıştır. Bu çalışmada, geleneksek sistemlere göre daha verimli, daha kompakt ve kullanım kolaylığı sağlayan bir sistem elde edilmiştir.
\end{abstract}

Anahtar kelimeler: Yenilenebilir Enerji Kaynağı, AC Motor Sürücüsü, Maksimum Güç Noktası İzleme (MPPT), Senkron Relüktans Motor (SynRM).

\section{Design and Control of SynRM Fed by Photovoltaic Panel}

\begin{abstract}
Synchronous reluctance motors (SynRM) have many advantages such as robust and simple construction, low cost production, high torque capability, per unit volume, field weakening capability, reduced power losses due to lack the of the rotor windings. Therefore, these motors have become interesting for many industrial and automotive applications. It is so difficult to produce high torque using small dimension motor and low voltage. In this paper, it is aimed that design of the SynRM which can operate with low voltage level generated by photovoltaic (PV) panels. This motor has a good dynamic, high starting torque and high efficiency. The motor was controlled by using maximum torque per amper (MTPA) control algorithm. Additionally, Maximum Power Point Tracking (MPPT) algorithm was used to obtain maximum power from the panels. This algorithm has automatically adjusted the speed-reference information of the motor and provided operating at the maximum efficiency of the system. In this study, a system having more efficient, more compact and ease of use was obtained than the traditional systems.
\end{abstract}

Key words: Renewable Energy, AC Motor Drive, Maximum Power Point Tracking (MPPT), Synchronous Reluctance Motor (SynRM).

\section{Giriş}

Teknolojideki gelişmelerle birlikte enerji ihtiyacının her geçen gün artması, enerjinin daha verimli kullanılmasını gerektirmektedir. Elektrik enerjisi tüketiminin önemli bir kısmını elektrik motorları oluşturmaktadır. Bu yüzden motorun ve kontrolünün verimliliği enerji tüketimini doğrudan etkilemektedir. İndüksiyon motorlar (IM) endüstriyel motorlar arasından en ucuz olanıdır. IM'lerin üretimi neredeyse bir yüzyıl boyunca devam etmektedir. Fakat IM'lerdeki kayma, motor verimliliğini azaltır ve hız/pozisyon geri bildirimi olmaksızın hızı kontrol etmek oldukça zordur. Ayrıca, hız-moment karakteristiği birçok motora göre kötü olduğu söylenebilir. IM'ler endüstriyle uygulamalar için son zamanlara kadar neredeyse rakipsizdi. Ancak son gelişmeler ile birlikte SynRM gibi daha iyi özelliklere sahip motorlar IM'lere rakip olmaya başlamıştır. SynRM'nin ilk teorik çalı̧maları 1923'te Kostko tarafindan yapılmıştır [1]. Fakat o dönemde elde edilen SynRM düşük verim ve zayıf moment karakteristiğinden dolayı endüstriyel amaç için uygun olmamıştır. Bu sebeplerden dolayı uzun bir süre boyunca bu motorun diğer elektrik motorlarına göre daha az önemli olduğu düşünülmüş̧ür [1]. Bazı araştırmacılar çalışmalarında relüktans motorun potansiyelinin farkına varmışlardır [2]. Fakat alan yönlendirme kontrollerin (FOC, Field Oriented Control) bu çalışmaların yapıldığı zamanlarda henüz bilinmemesinden dolayı bu

\footnotetext{
${ }^{*}$ Sorumlu yazar: gboztas@ @irat.edu.tr. Yazarların ORCID Numarası: ${ }^{1} 0002-1720-1285,{ }^{2} 0001-8142-1146,{ }^{3} 0003-0491-8348$
} 
araştırmacılar pratikte relüktans motoru elde edememişlerdir. IM'lere benzer stator yapısına sahip SynRM'ler üzerine ilgi 1960'lara dayanmaktadır. Bu motorun kalkış yapabilmesi için kafes sargılarına ihtiyaç duyulmuştur. Güç elektroniği teknolojisinin gelişmesiyle birlikte tüm bu problemler giderilmiştir. Elektrik enerjisinin tasarrufu için artan ihtiyaçlar ile birlikte endüstriyel üreticilerin SynRM'lere olan ilgisi artmıştır [2-4]. Daha sonraki yıllarda değişken frekanslı sürücülerin kullanılmasıyla birlikte SynRM'lerin daha doğru analiz edilmesi ve daha doğru motor tasarımı yapılması sağlanmıştır. 1960 ve 1980 yılları arasında Enine Laminasyonlu Anizotropi (TLA) ve Eksenel Laminasyonlu Anizotropi (ALA) yapısı üzerine çalışmalar yapılmıştır [2, 4].

Son zamanlarda tasarımdaki gelişmeler sayesinde SynRM'nin moment kapasitesi ve enerji verimliliği arttırılmıştır. Ancak SynRM'lerin ek rotor sargıları olmadan şebekeye doğrudan bağlantı yaparak kalkış yapması mümkün değildir. Enerji kayıplarını minimize etmek ve sistemin performansını arttırmak için elektrik motorlarının frekans konverterleri tarafindan beslenmesi son zamanlarda popüler olmuştur. Böylece, değişken hız uygulamalarında SynRM'lerin frekans konverterleriyle ile birlikte kullanılması geleneksel IM'lerin yerini almasını mümkün kılmıştır. SynRM'lerin rotor yapısı IM'lerin rotor yapısından daha basit ve üretimi oldukça kolaydır. SynRM'nin daha basit bir yapı sunması, onu birçok amaç için ideal hale getirmektedir. Ayrıca, enerji kayıplarının düşük olmasından dolayı bu motorların verimleri IM'lere göre daha yüksektir. SynRM'nin düşük enerji kayıplarından dolayı aynı boyuttaki IM'lerin momentinden \% (15-20) daha fazla moment üretebilir [5].

Güç elektroniği tabanlı sürücülerin gelişimiyle elde edilen yeni imkânlardan dolayı SynRM, kapalı çevrim kontrolü altında kolayca kontrol edilebilir ve çalıştırılabilir [6-9]. Alan yönlendirmeli kontrol (FOC-Field Oriented Control) [8] doğrudan moment kontrolü (DTC-Direct Torque Control) veya benzer yöntemler SynRM için literatürde sunulmuştur [6]. Kapalı çevrim kontrolü altında SynRM'nin, yüksek verimlilikle değişken hız çalışması istenildiğinde SynRM'nin güçlü endüstriyel rakibi olan IM ile karşılaştırıldığında bazı avantajları olduğu gösterilmiştir.

Lokal olarak çalışabilen düşük güçlü sistemlerin şebekeden bağımsız olarak güneş enerjisi yardımıyla üretilen elektrik enerjisinden beslenmesi büyük bir avantaj sağlamaktadır. Bilindiği gibi güneş enerjisini elektrik enerjisine çevirmek için PV paneller kullanılmaktadır. Bu hücrelerin ürettikleri gerilim seviyesi çok düşük ve Doğru Akım (DA) gerilim olduğu için günlük yaşantımızda kullanılan $220 \mathrm{~V}, 50 \mathrm{~Hz}$ Alternatif Akım (AA) gerilime çıkarılması ve ayarlanması gerekmektedir. Bu yüzden PV hücrelerden elde edilen DA gerilim boost konverter yardımıyla yükseltilmekte ve bir inverter yardımıyla şebeke gerilimine dönüştürülmektedir. Bununla birlikte sistemden daha yüksek verim elde etmek için MPP'de çalışma sağlanmalıdır. MPPT, boost konverter veya akü şarj cihazı yardımıyla gerçekleştirilmektedir. Yüksek maliyetli ve karmaşık bir yapıya sahip olan bu sistemler, birçok firma tarafindan üretilmektedir [10].

Bu çalışmada; akü, akü şarj yönetim sistemi ve boost konverter kullanılmadan sadece motor ve sürücü yapısı kullanılarak düşük gerilimle çalışabilen bir sistem tasarlamaktır. Bu sistemde güneşten elde edilen düşük gerilim seviyesini artırmaya gerek kalmamaktadır. Böylece boost konverter ve karmaşık güç elektroniği yapısının bir kısmı ortadan kalkmaktadır. Elde edilen bu sistem, şebekeden bağımsız olarak düşük gerilimle çalışabilen bir elektrik motorundan ve inverterden oluşmaktadır. Böylece daha sağlam, daha ucuz ve daha kompakt bir yapı elde edilebilmiştir. Ayrıca panellerden maksimum güç elde edilebilmesi için MPPT algoritması motorun hız-referans bilgisini otomatik olarak değiştirerek sistemin maksimum verimde çalışmasını sağlamıştır. Bu çalışmada, MotorSolve programı kullanılarak SynRM tasarlanmıştır.

\section{SynRM'nin Matematiksel Modeli}

SynRM rotorunda alan sargısı veya mıknatıs mevcut değildir. Şebeke ile doğrudan kalkış yapmayı sağlayan rotordaki kısa devre çubuklu kafes kullanılmadığı için motor uygun bir sürücü kontrolü ile sıfir hızda bile senkron olarak başlatılması sağlanabilir. Geleneksel bir SynRM'nin eşdeğer devresi Şekil 1'de verilmiştir.

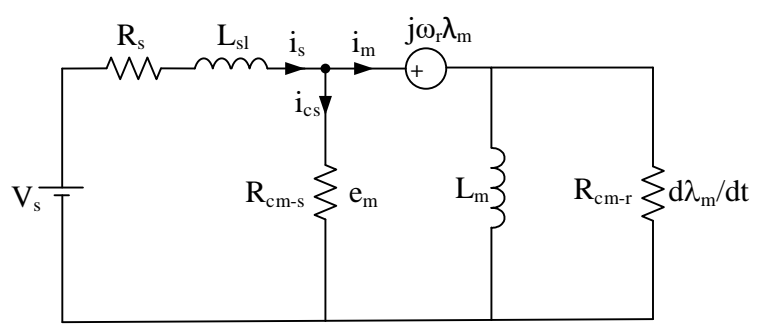

Şekil 1. SynRM'nin eşdeğer devresi. 
SynRM denklemleri Denklem (1)-(3) arasında verilmiştir.

$V_{s}=R_{s} i_{s}+\mathrm{j} \omega L_{s l} i_{s}+e_{m}$

$e_{m}=\frac{d \lambda_{m}}{d t}+\mathrm{j} \omega \lambda_{m}$

$i_{s}=i_{c s}+i_{m}$

Burada $V_{s}$ ve $i_{s}$ stator gerilim ve akımıdır. $R_{s}$ ve $L_{s l}$, stator direnci ve sızıntı indüktansıdır. $e_{m}$, hava boşluğu elektromotor kuvvetidir. $i_{c s}$ ve $i_{m}$, stator çekirdeği demir kaybı akımını ve stator mıknatıslanma akımını göstermektedir. Ayrıca $\lambda_{m}$, hava boşluğu akı bağlantısıdır.

SynRM'nin moment ifadesi Denklem (4)'de verilmiştir.

$T=\frac{3}{2} \frac{P}{2}\left(\lambda_{d s} i_{q s}-\lambda_{q s} i_{d s}\right)$

Burada $\lambda_{d s}$ ve $\lambda_{q s}, d$ ve $q$-eksen akılarıdır. $\mathrm{i}_{\mathrm{ds}}$ ve $\mathrm{i}_{\mathrm{qs}}$ stator $d$ ve $q$-eksen akımlarıdır. $P$ kutup sayısı, $L_{d s}$ ve $L_{q s}$ stator indüktanslarıdır.

SynRM'de $d$ ve $q$ eksen indüktanslarının oranı $\left(L_{d} / L_{q}\right)$ çıkıntı oranını ( $\xi$ ) temsil eder. Motordan yüksek moment elde etmek için çıkıntı oranının arttırılması gerekmektedir [8, 11-15]. Yüksek performans için hedeflenen tasarım, yüksek $L_{d}$ elde etmek için $d$-eksendeki akıyı yönlendirmeyi sağlayarak ve $L_{q}$ parametresini düşürmek için $q$-eksenine akı bariyeri koyularak yapılır.

\section{SynRM Tasarımı ve Kontrolü}

Motor tasarımında ilk olarak motorun mekanik kısıtlamaları belirlenmelidir. Motor gövdesi; sargıları, rulman yataklarını ve diğer mekanik parçaları dış ortamdaki nemden, kimyasallardan, mekanik hasarlardan ve aşınmaya karşı korumak için kullanılmaktadır. Bu çalışmada; 4-inç ve 0,65 kW değerinde pompa motor tasarımı yapılmıştır. Stator dış çapı, motor gövdesinin iç çapı ile belirlenen tolerans değerinde uygunluğunun sağlanabilmesi için 90,35 mm olarak belirlenmiştir. Ayrıca stator 30 oluklu olarak kullanılmıştır. Motorun rotor yapısı Şekil 2'de verilmiştir. Rotorun hem $d$-eksen indüktansını arttırmak hem de $q$-eksen indüktansını azaltmak için rotor nüvesine $q$-ekseni boyunca akı bariyerleri yerleştirilmiştir. Tasarlanan motor Şekil 2'de görüldüğü gibi 4-bariyerlidir. Rotorun diş yarıçapı $\left(R_{o}\right) 24,5 \mathrm{~mm}$ ve iç yarıçapı $1\left(R_{i}\right) 8 \mathrm{~mm}$ 'dir.

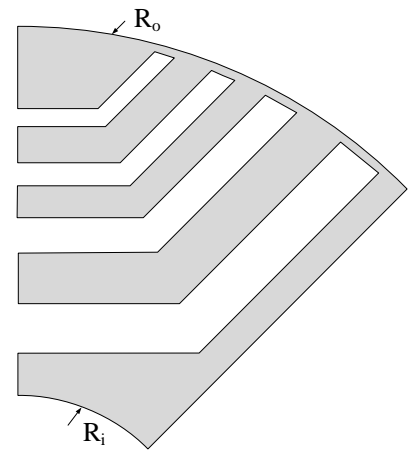

Şekil 2. Tasarlanan motorun rotor yapısı.

SynRM moment üretiminde en büyük etkiyi rotor geometrisi oluşturmaktadır. İlerleme açısının üretilen moment üzerinde etkisi oldukça önemli bir parametredir. Bu çalışmada; tasarlanan motor için en iyi ilerleme açısı $47^{\circ}$ olarak belirlenmiş̧tir. Elektriksel derece cinsinden rotorun $d$-ekseni ile $a$-fazı sargısının merkezi arasındaki açı ilerleme açısına eşit olduğu zaman a-fazının akımı maksimum olur.

Belirtilen değerlere göre tasarlanan motorun yapısı Şekil 3'te gösterilmiştir. 


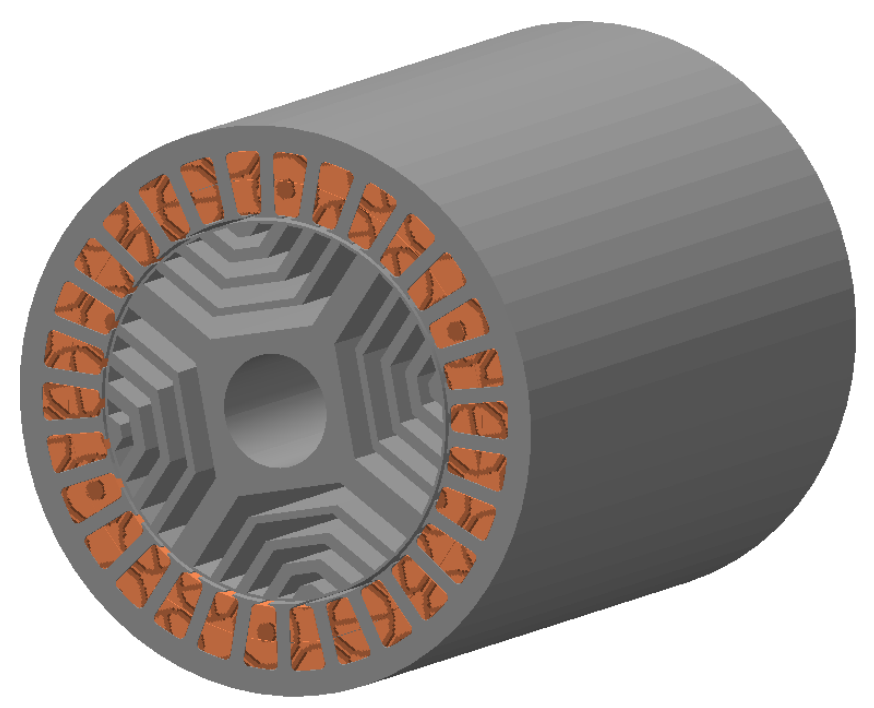

Şekil 3. Tasarlanan motorun rotor ve stator yapısı.

MotorSolve programıyla tasarlanan motorun hem MotorSolve programında hem de Magnet programında analiz sonuçları Şekil 4'te verilmiştir [16-17]. Motorun maksimum akı değeri yaklaşık 2 T'dir. Motorun akı dağılımı ve yönlendirmeleri arzu edildiği şekilde gerçekleşmiştir.

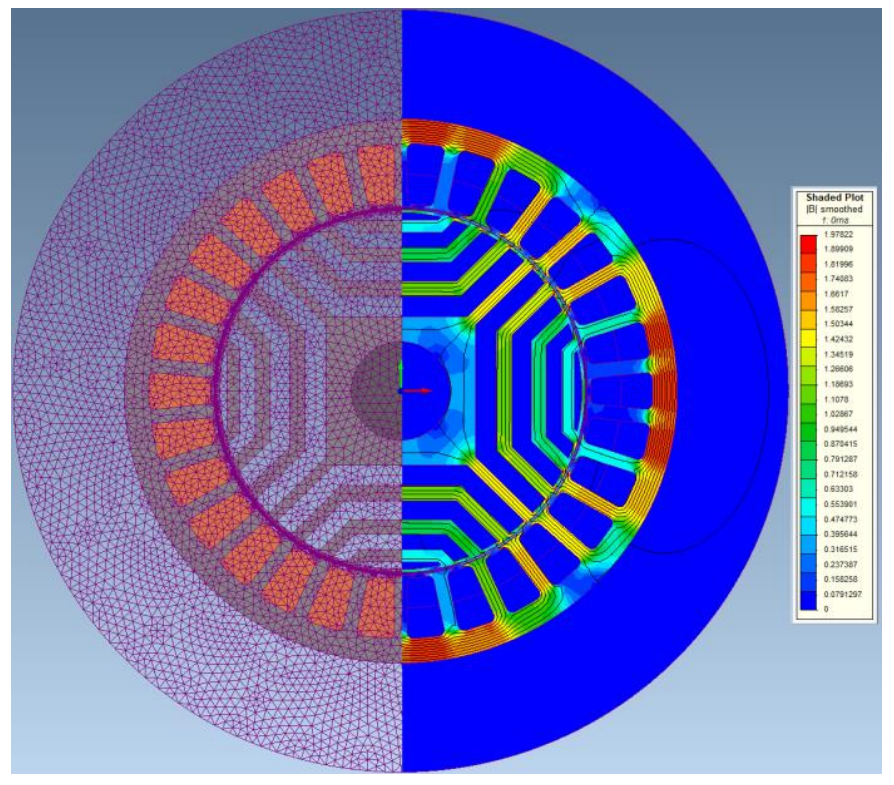

Şekil 4. Sol: Motor ızgara görünümü, Sağ: Motor akı çizgisi dağılımı.

Tasarlanan motorun $10 \mathrm{kHz}$ anahtarlama frekansında Şekil 5 'te görüldüğü gibi hıza göre verim, moment ve çıkış gücü eğrileri verilmiştir [16]. Motor sabit moment bölgesinde çalıştırılmıştır. Motor sürekli durumda nominal hıza kadar yaklaşı $2 \mathrm{Nm}$ moment üretebilmiştir. Motorun çıkış gücü yaklaşık $633 \mathrm{~W}$ olarak ölçülmüştür. Motor verimi tam yük koşulları altında yaklaşı $\% 85$ civarındadır. Sargı kayıpları 88,2 W, demir kayıpları 19,8 W ve Darbe Genişlik Modülasyon sürücü kayıpları 18,4 W olarak hesaplanmıştır. Ayrıca sürtünme ve vantilasyon kayıpları ihmal edilmiştir. 


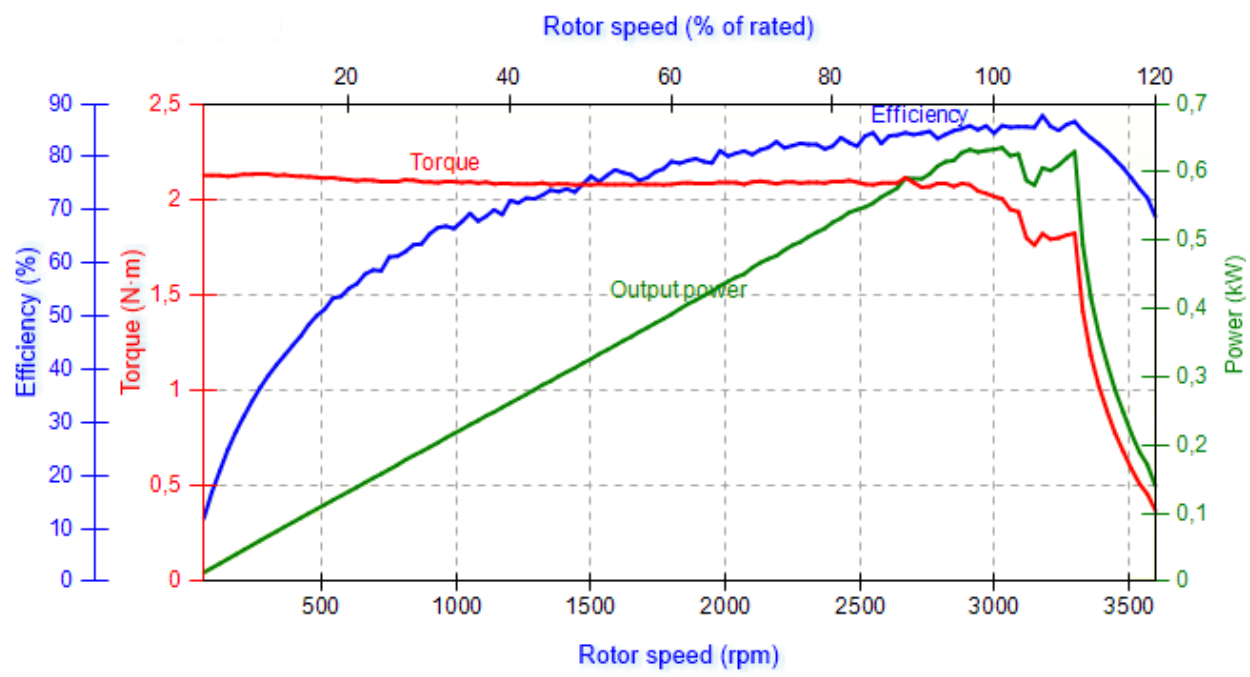

Şekil 5. Tasarlanan motorun moment, verim ve çıkış gücünün hıza göre değişim eğrileri.

Şekil 6' da tasarlanan motora ait verim haritası verilmiştir. Motor veriminin hız ile doğru orantılı olarak arttığı ve hız arttıkça üretilen maksimum momentin azaldığı görülmektedir. Motor nominal hızda çalışırken; \%10 yük değerinde ve üstündeki değerlerde yaklaşık \%85-87 arasında verime sahip olduğu görülmektedir.

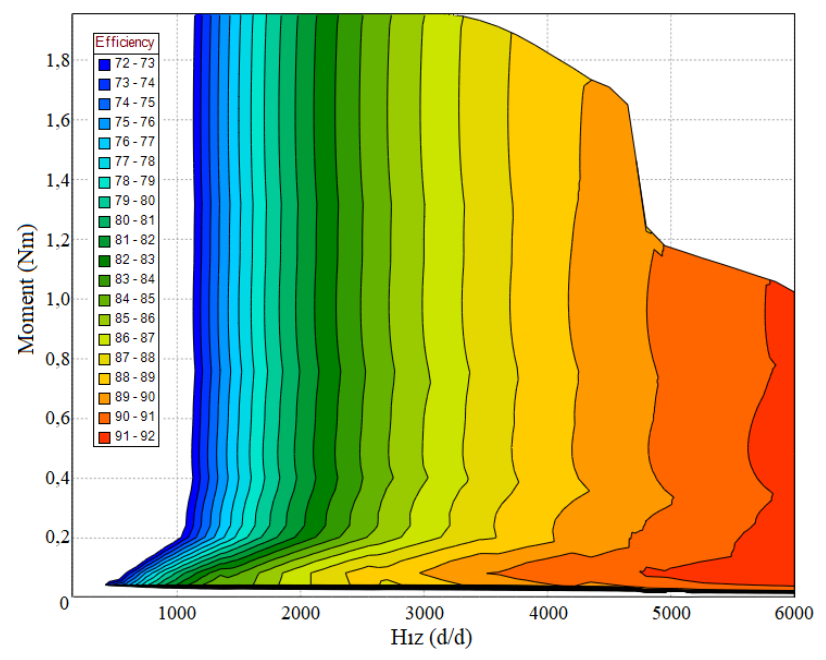

Şekil 6. Tasarlanan motorun verim haritası.

\section{Benzetim Sonuçları}

AA motor kontrolü; $d$ ve $q$-eksen akımlarıyla gerçekleştirilmektedir. Bu çalışmada; akım başına düşen momenti maksimum yapan MTPA kontrol algoritması kullanılmıştır. MTPA stratejisi, verimlilik açısından önemlidir. Bu kontrol algoritmasında; $d$ ve $q$-eksen akımları eşit tutulmaktadır. Böylece moment/akım oranının maksimum olması sağlanmaktadır. Işınım ve sıcaklıkla birlikte güneş hücrelerinin değişken MPP'lerinden dolayı MPPT algoritmaları PV uygulamaları için gereklidir. Literatürde birçok farklı MPPT algoritmaları mevcuttur. Bu çalışmada; Değiştir ve Gözetle-P\&O (Perturb and Observe) algoritması sisteme uygun olarak modifiye edilerek kullanılmıştır.

Tasarlanan motor ve kontrolü Şekil 7'de verilen MATLAB benzetim ortamında test edilmiştir. 

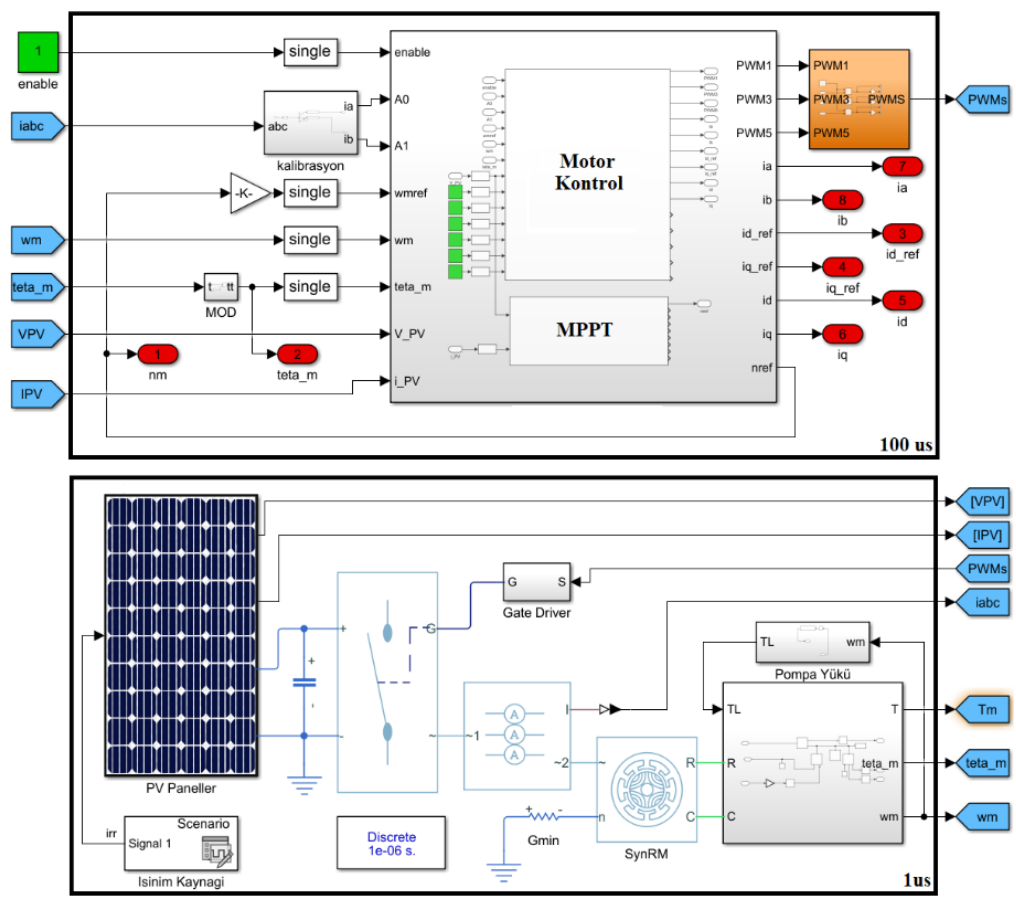

Şekil 7. PV panel için oluşturulan benzetim ortamı.

Strasıyla $250 \mathrm{~W} / \mathrm{m}^{2}, 400 \mathrm{~W} / \mathrm{m}^{2}$ ve $1000 \mathrm{~W} / \mathrm{m}^{2}$ 1şınım koşulları altında ve $25^{\circ} \mathrm{C}$ sabit sıcaklık için sisteme ait değişkenler incelenmiştir. Hız, akım, verim, PV panel akımı, gerilim ve güç eğrileri Şekil 8'de gösterilmiştir. Motor hızı, ışınım değişimine göre MPPT algoritması ile ayarlanmışırı. Sistemde 2 seri, 2 paralel olmak üzere toplamda 4 adet PV (LG395N2T-A5) panel kullanılmıştır. Şekil 8a'da görülüğü gibi ışınım arttıkça motor hızının nominal hıza yaklaştığı görülmektedir. $1000 \mathrm{~W} / \mathrm{m}^{2}$ ıșınım koșulları altında motor verimin yaklaşık \%83 olduğu Şekil 8b'de verilmiştir. Şekil 8c'de görüldüğü gibi MTPA kontrol algoritması sayesinde $i_{d}$ ve $i_{q}$ akımları eşitlenmiştir. Böylece daha yüksek moment elde edilmesi sağlanmıştır.
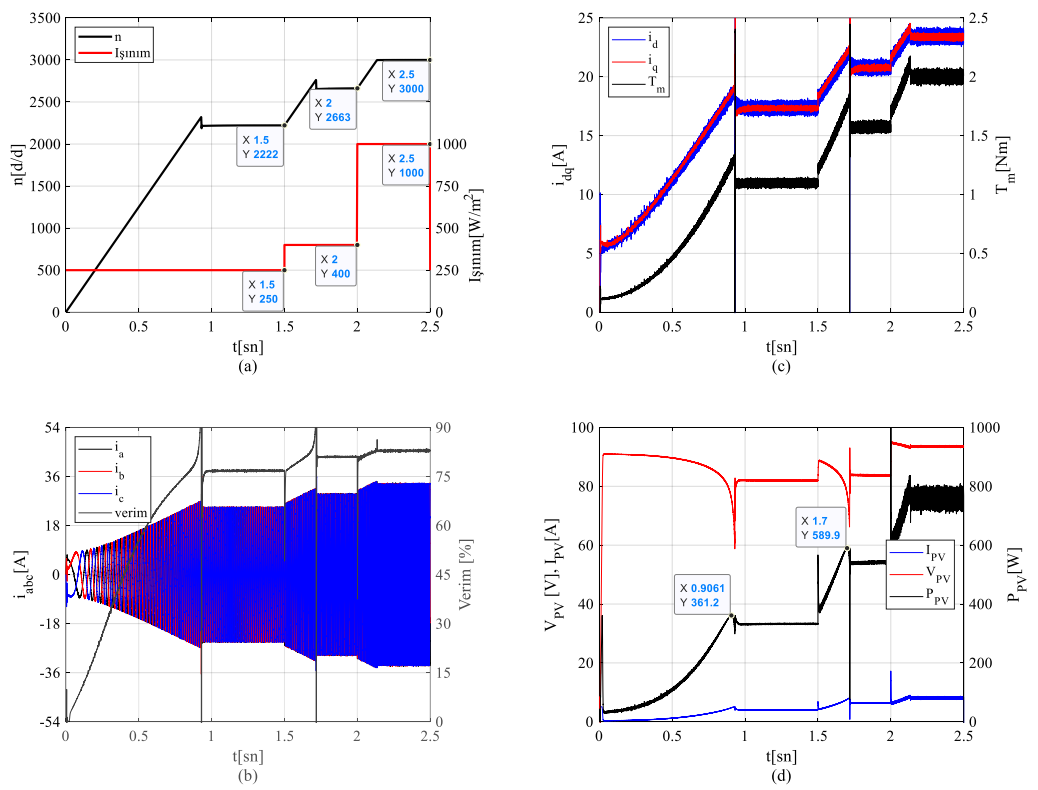

Şekil 8. $25^{\circ} \mathrm{C}$ sabit sıcaklık için; a) Hız ve Işınım, b) Stator akımları ve verim, c) $i_{d}, i_{q}$ ve $T_{m}$ momenti, d) PV panele ait akım, gerilim ve güç eğrileri. 
Şekil 8'de verilen aynı 1şınım koşulları altında $60^{\circ} \mathrm{C}$ sıcaklık için benzer çalışma durumları Şekil 9' da verilmiştir. Şekil 8 a ve Şekil 9a karşılaştırıldığında sıcaklık arttıkça benzer ışınım koşullarında motor referans hızının azaldığı görülmektedir. Ayrıca motor 3-faz akımları, motor $i_{d}, i_{q}$ akımları ve $T_{m}$ momentine ait değişimler ile PV panel akım, gerilim ve güç eğrileri sırasıyla Şekil 9b, Şekil 9c ve Şekil 9d'de verilmiştir.
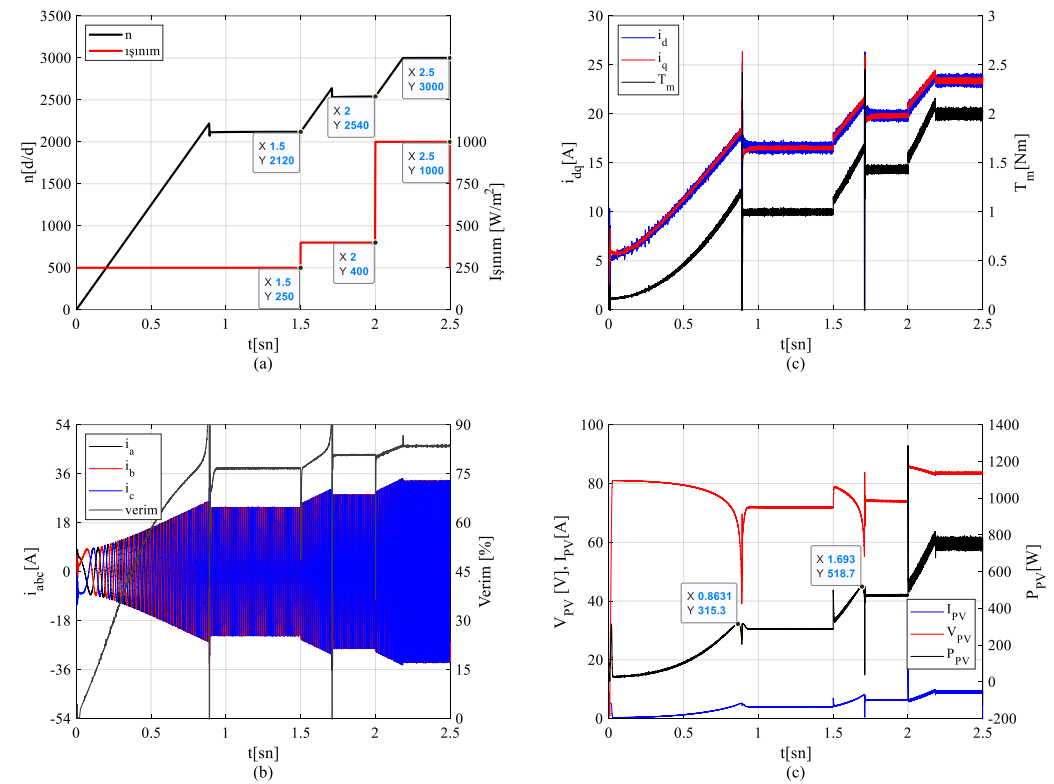

Şekil 9. $60^{\circ} \mathrm{C}$ sabit sıcaklık için; a) Hız ve Işınım, b) Stator akımları ve verim, c) $i_{d}, i_{q}$ ve $T_{m}$ momenti.

Aynı 1şınım koşulları altında ortam sıcaklığ $125^{\circ} \mathrm{C}$ 'den $60^{\circ} \mathrm{C}^{\prime}$ ye çıktığında meydana gelen değişiklikler Şekil 10 'da detaylı olarak verilmiştir. Sicaklık farkından dolayı $250 \mathrm{~W} / \mathrm{m}^{2}$ 1şınımda $45 \mathrm{~W}$ 'lık bir güç farkı oluştuğu Şekil $10 \mathrm{c}$ ve Şekil 10e'de görülmektedir. Benzer şekilde $400 \mathrm{~W} / \mathrm{m}^{2}$ 1şınımda ise güç farkının yaklaşık $71 \mathrm{~W}$ olduğu Şekil 10d ve Şekil 10f'de gösterilmiştir. Benzetim sonuçları hem MTPA hem de MPTT algoritmalarının doğru çalıştığını göstermektedir.
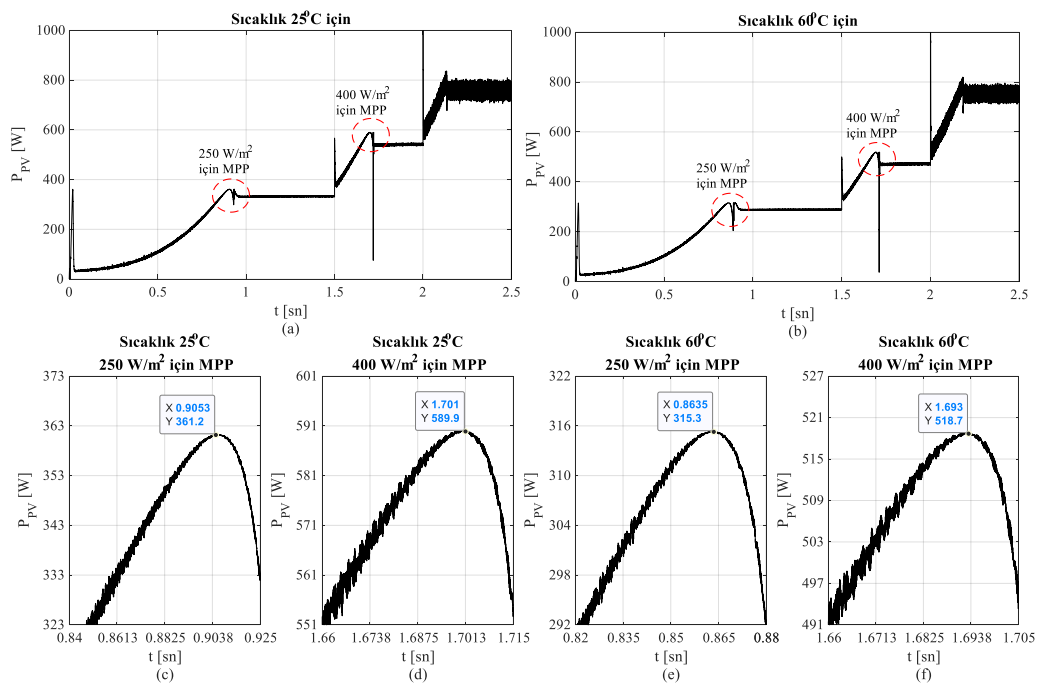

Şekil 10. Farklı 1şınımlardaki $P_{P V}$ gücü değişimi; a) $25^{\circ} \mathrm{C}$ için b) $60^{\circ} \mathrm{C}$ için, $25^{\circ} \mathrm{C}$ 'de MPP noktası; c) $250 \mathrm{~W} / \mathrm{m}^{2}$ için, d) $400 \mathrm{~W} / \mathrm{m}^{2}$ için, $60^{\circ} \mathrm{C}$ 'de MPP noktas1; e) $250 \mathrm{~W} / \mathrm{m}^{2}$ için, f) $400 \mathrm{~W} / \mathrm{m}^{2}$ için MPP noktası. 


\section{Sonuç}

$\mathrm{Bu}$ çalışmada, düşük gerilim seviyesinde çalışabilen yüksek verimli bir SynRM tasarlanmıştır. Motor çıkış gücü $650 \mathrm{~W}$ civarında elde edilebilmiştir. Motor nominal hızına kadar sabit moment değerinde çalışabilmiştir. Ayrıca motor nominal hız ve yük koşulu altında maksimum verimini sağlayabilmiştir. Tasarlanan motor yaklaşık \%85 verime sahip olduğu hesaplanmıştır. Motordan maksimum performans alabilmek için MTPA kontrolü kullanılmıştır. Bu kontrol algoritmasında, d ve q eksen akımları birbirine eşit tutularak aynı yük koşullarında statordan çekilen akım minimize edilmeye çalışılmıştır. Tasarlanan motor kontrolünde, güneş panellerinden elde edilen düşük gerilim seviyesi yükseltilmeden doğrudan inverter dc-hattı olarak kullanılmıştır. PV panelden maksimum verim elde edebilmek için geleneksek MPPT algoritması modifiye edilerek motor referans hızını belirlenmesi sağlanmıştır. MPP noktası değiştiğinde motor hız referansı değiştirilerek bu noktada çalş̧ması sağlanmıştır.

Bu çalışmada elde edilen sonuçlara göre; düşük maliyetli, yüksek verimli ve sağlam bir yapıya sahip olan SynRM'nin düşük gerilim ile çalışabileceği gösterilmiştir.

\section{Teșekkür}

Bu çalışma için Türkiye Bilimsel ve Teknolojik Araştırma Kurumuna (TUBİTAK)-116E116 nolu proje ile vermiş oldukları finansal destekten dolayı teşekkür ederiz. Bu makale Güllü BOZTAŞ’a ait doktora tezinden üretilmiştir.

\section{Kaynaklar}

[1] Kostko JK. Polyphase reaction synchronous motors. J Am Inst Electr Eng. 1923; 42(11): 1162-1168.

[2] Cruickshank AJO, Anderson AF, Menzies RW. Theory and performance of reluctance motors with axially laminated anisotropic rotors. Proc Inst Electr Eng. 1971;118(7): 887-894.

[3] Douglas JFH. Pull-in criterion for reluctance motors. Trans Am Inst Electr Eng Part II Appl Ind. 1960; 79(3): 139-142.

[4] Cruickshank AJO, Menzies RW, Anderson AF. Axially laminated anisotropic rotors for reluctance motors. Proc Inst Electr Eng. 1966; 113(12): 2058-2060.

[5] Boglietti A, Pastorelli M. Induction and synchronous reluctance motors comparison. In: 2008 34th Annual Conference of IEEE Industrial Electronics; 10-13 Nov. 2008; Orlando, FL, USA: IEEE. pp. 2041-2044.

[6] Boldea I. Reluctance Synchronous Machines and Drives. Clarendon Press, 1996.

[7] Fernandez-Bernal F, Garcia-Cerrada a., Faure R. Efficient control of reluctance synchronous machines. IECON '98 Proc 24th Annu Conf IEEE Ind Electron Soc; 1998; Aachen, Germany, pp. 923-928.

[8] Betz RE. Theoretical aspects of control of synchronous reluctance machines. IEE Proc B Electr Power Appl. 1992; 139(4): 355-364.

[9] Xu L, Xu X, Lipo TA, Novotny DW. Vector control of a synchronous reluctance motor including saturation and iron loss. IEEE Trans Ind Appl. 1991; 27(5): 977-985.

[10] Aydogmus O. Design of a solar motor drive system fed by a direct-connected photovoltaic array. Adv Electr Comput Eng. 2012; 12(3): 53-58

[11] Lipo TA. Synchronous Reluctance Machines-A Viable Alternative for AC Drives? Electr Mach Power Syst. 1991; 19(6): 659-671.

[12] Staton DA, Miller TJE, Wood SE. Maximising the saliency ratio of the synchronous reluctance motor. IEE Proc B Electr Power Appl. 1993; 140(4): 249-259.

[13] Betz RE, Lagerquist R, Jovanovic M, Miller TJE, Middleton RH. Control of synchronous reluctance machines. IEEE Trans Ind Appl. 1993; 29(6): 1110-1122.

[14] Chiba A, Fukao T. A closed-loop operation of super high-speed reluctance motor for quick torque response. IEEE Trans Ind Appl. 1992; 28(3): 600-606.

[15] Tuovinen T. Model-based position estimation for synchronous reluctance motor drives. PhD, Aalto University, Finland, 2014.

[16] Boztas G, Aydogmus O, Caner M, and Guldemir H. Design, optimisation and implementation of low-voltage synchronous reluctance motor for solar-powered systems. IET Power Electronics. 2019; 12(7): 1679-1685.

[17] Boztas G. Düşük Gerilim ile Beslenen Senkron Relüktans Motor ve Sürücü Tasarımı, Doktora Tezi, Firat Üniversitesi, Elazı̆̆g, Türkiye, 2019. 